\title{
Das Todesjahr des Psellos und die Abfassungszeit der Dioptra.
}

In dieser Zeitschrift II S. 150 identifiziert H. Seger den bei Attaleiates ërwähnten Michael aus Nikomedien mit Michael Psellos und setzt dementsprechend den Tod des letzteren in den Ausgang des Jahres 1078. ${ }^{1}$ ) Die Kombination ist sehr ansprechend. Doch erhebt sich gegen sie ein Bedenken.

In den meisten Hss der Dioptra des Philippos Monotropos ${ }^{2}$ ) steht zu Anfang eine kurze Vorrede des Psellos, in welcher das Buch als erbaulich und für das Seelenheil nützlich empfohlen wird. Ihm werden, wie es scheint, in den Hss auch einige Zusätze zum Werke des Philippos (meist Parallelstellen aus der Bibel und den Kirchenvätern) zugeschrieben. - Über die Zeit der Abfassung der Dioptra haben wir ein Zeugnis des Autors selbst, das aber bisher nicht richtig verstanden worden ist. Er sagt III c. 8, dafs seit Christi Geburt bis zu seiner Zeit 1105 Jahre verflossen seien: puto namque a Christo in praesens tempus annos evolutos esse mille centum quinque, sicut accurate rationem putando inveni. Darnach wird allgemein die Abfassung der Dioptra in das Jahr $1105 \mathrm{n}$. Chr. gesetzt. Doch steht damit im Widerspruch die gleich darauf folgende Angabe: optimus autem Alexius

1) Auf unzureichende Gründe gestützt setzt Bezobrazov (der byzantinische Schriftsteller und Staatsmann Michael Psellos, Moskau 1890 S. 122) den Tod des Psellos vor den Regierungsantritt des Nikephoros Botaneiates.

2) So im Paris. 2748, Paris. 2874, Mosq. 148 (Matth. 149) und in den Hss, welche die Utberarbeitung des Phialites bieten, wie Paris. 2747 und der von Pontanus benutzte August. Ebenso in den russischen Übersetzungen, siehe Bezobrazov, Joumal des Minist. f. Volksaufkl. 1893 XI S. 29. Bedauerlicherweise giebt es noch immer keine Ausgabe der Dioptra, und man ist nach wie vor auf die (nach der Bearbeitung des Phialites gemachte) Übersetzung des Pontanus angewiesen. Und doch ist das Werk des Philippos von Interesse als byzantinische Bearbeitung des weitverbreiteten „Streites zwischen Seele und Leib“. Eine andere byzantinische Bearbeitung dieses auf antike Muster zurückgehenden, bei allen Völkern des Mittelalters beliebten Motives ist die fälschlich dem Gregorios Palamas zugeschriebene 'Prosopopoiia'. 

decimum sextum (sc. annum) in imperio nunc agit. Da Alexios Komnenos im April 1081 den Thron bestieg, werden wir auf die letzten acht Monate des Jahres 1096 oder die ersten vier des Jahres 1097 geführt. Der Widerspruch erklärt sich daraus, dafs Philippos, wie er selbst angiebt, seit Erschaffung der Welt bis Christi Geburt 5500 Jahre rechnet, während, wie bekannt, letzteres Ereignis gewöhnlich in das Jahr 5509 der Welt gesetzt wird. Die Addition der 5500 Jahre v. Chr. und der 1105 Jahre n. Chr. ergiebt 6605; dies Jahr der byzantinischen Ara stimmt zum 16. Regierungsjahre des Alexios und zu den Jahren des Sonnen- und Mondcyklus, wie sie Philippos angiebt: ad praesentem usque indictionem (das Indiktionsjahr selbst wird nicht bezeichnet), secundum quam duodecima lunae, solis autem vigesima quinta periodus necessario circumacta est. Als engeren terminus post quem für die Abfassung der Dioptra erhalten wir dadurch den 1. Sept. 1096. Da Philippos ferner seit Christi Geburt 1105, seit Christi Tode aber 1072 (nicht 1073) Jahre rechnet, so läfst sich schliefsen, dafs er sein Werk nach Weihnachten 1096, aber vor Ostern 1097 geschrieben hat.

Michael Psellos mufs also Anfang 1097 noch am Leben gewesen sein, wenn anders die Vorrede und die Zusätze der Dioptra wirklich von ihm stammen, woran zu zweifeln kein Grund vorhanden zu sein scheint.

Kiew.

A. Sonny. 